\title{
REGULAÇÃO PATERNALISTA EM TEMPOS DE PANDEMIA
}

\section{Andre Martins Bogossian*}

\section{Resumo:}

O objetivo deste artigo é discutir três ordens de razões contra justificações paternalistas na regulação, usando exemplos hipotéticos aplicáveis ao contexto da pandemia da COVID-19: problemas de processamento informacional e de racionalidade limitada decisional dos reguladores, além de problemas relativos a deliberações em grupo e questões de capacidade institucional; aplicabilidade das teorias da captura e das teorias institucionais; e problemas inerentes ao direito, pelo fato de que as normas que veiculam medidas paternalistas necessitam ser especialmente congruentes, mas, ao mesmo tempo, precisam lidar com os problemas de inclusividade e indeterminação do material linguístico usado.

Palavras chave: regulação; paternalismo; pandemia; racionalidade limitada; teoria da captura; teoria institucional; congruência normativa

\section{PATERNALIST REGULATIONS IN PANDEMIC TIMES}

\begin{abstract}
:
This paper aims to discuss three orders of reasons against paternalist justifications for regulation, using hypothetical regulations for the COVID-19 pandemic context: the first, related to the capacity of the regulator, deals with informational and bounded rationality issues applied to regulators, as well as questions of group deliberation of institutional capacity; the second assesses the applicability of capture and institutional theories; and finally problems inherent to the legal material used to issue regulations such as of inclusiveness and indeterminacy, considering the particular need of paternalistic regulations to be congruent to their first order (paternalistic) justifications.
\end{abstract}

Keywords: regulation; paternalism; pandemic; bounded rationality; capture theory; institutional theory; normative congruence

\section{O problema}

A pandemia do novo coronavírus (Sars-Cov-2, que provoca a COVID-19, considerada como tal pela Organização Mundial da Saúde ${ }^{1}$, tem imposto uma série de desafios a todos os países diante da impressionante velocidade de propagação do vírus, apesar

\footnotetext{
* Doutorando em Direito da Regulação na FGV Direito Rio (2020-). Master of Laws (LL.M.) pela Harvard Law School (2016). Mestre em Teoria do Estado e Direito Constitucional na Pontifícia Universidade Católica do Rio de Janeiro (2015). Visiting Research Fellow na Brown University (2014). Graduado magna cum laude pela Faculdade Nacional de Direito da Universidade Federal do Rio de Janeiro (2010). andre.bogossian@ @gv.edu.br.

https://www.who.int/dg/speeches/detail/who-director-general-s-opening-remarks-at-the-media-briefing-oncovid-19---11-march-2020. Acesso em 9 de maio de 2020.
} 
da relativa baixa letalidade. Diante deste cenário, diferentes respostas têm sido testadas pelos países, com variados graus de sucesso. Em geral, tem-se favorecido em larga escala as medidas de distanciamento social e isolamento dos grupos de risco. ${ }^{2}$

Contudo, é possível cogitar de outras medidas que poderiam ser pensadas não com o propósito de promoção da saúde pública em relação especificamente à pandemia, mas como formas de proteção dos indivíduos de si mesmos em tempos de tamanhas limitações. Considerando que boa parte da população está em isolamento ou quarentena em suas próprias casas, ${ }^{3}$ ainda que em sistemas de teletrabalho, há espaço para se cogitar academicamente de certas intervenções regulatórias de cunho paternalista.

Ainda que se saiba que tais medidas, na prática, não tenham ainda sido discutidas pelas autoridades públicas, há que se pensar que tipo de situação poderia ser cogitada caso a necessidade de isolamento permaneça ou até se intensifique, passando ao estágio do lockdown, como até já verificado em algumas cidades do país. ${ }^{4}$ Ou seja, diante do cenário de isolamento social por diversos meses, reguladores paternalistas podem se tornar particularmente interessados em promover o bem estar de indivíduos em suas casas por meio das mais variadas técnicas de regulação (BALDWIN, CAVE, LODGE, 2012, p.106), como comando e controle, disposição de incentivos positivos e negativos, modelagem da arquitetura de decisões - os nudges (SUNSTEIN E THALER, 2008) -, entre outros. Este artigo se preocupa de identificar que medidas regulatórias de caráter paternalista poderiam ser cogitadas, classificando-as dentre as formas de paternalismo existente e avaliando a sua pertinência e problemas.

Sendo possível supor certas medidas regulatórias de caráter paternalista, das mais brandas (como as afetas aos campos de incentivos e nudges) às mais coercitivas (no campo das estratégias de comando e controle), a hipótese desse artigo é a de que as objeções a certas

\footnotetext{
${ }^{2}$ A União, por meio da Lei $n^{\circ} 13.979 / 20$, disciplinou um conjunto de medidas para o enfrentamento da pandemia em seu artigo $3^{\circ}$, tais como isolamento, quarentena, realização compulsória de exames e testes laboratoriais, restrição excepcional de entrada e saída do país, entre outras. Todas as medidas estabelecidas naquela lei, contudo, objetivam a proteção da coletividade, nos termos do próprio art. $1^{\circ}, \S 1^{\circ}$. Antes, a Portaria $n^{\circ} 188$, de 03 de fevereiro de 2020, do Ministério da Saúde, já dispunha sobre a Declaração de Emergência em Saúde Pública de Importância Nacional (ESPIN) em decorrência da Infecção Humana pelo novo coronavírus.

${ }^{3}$ Ainda que, como se sabe, há diversos segmentos da sociedade que não podem permanecer em isolamento, pela sua vital importância ao abastecimento de suprimentos necessários à sociedade - como alimentos, fármacos - ou à promoção da ordem e saúde públicas, ou ainda a manutenção das atividades econômicas, como bancos.

4 A exemplo da região metropolitana de São Luis - MA, imposto por decisão judicial em Ação Civil Pública no processo 0813507-41.2020.8.10.0001.
} 
medidas regulatórias de caráter paternalista mais coercitivas são intransponíveis, ainda que haja problemas a todas as formas de regulação paternalista já apontados na doutrina (BOGOSSIAN e DE LUCA, 2015). Para tanto, inicialmente serão feitas breves considerações a respeito da regulação; a seguir, pretende-se oferecer um conceito de paternalismo jurídico e suas espécies, estabelecendo sua fronteira com outros conceitos com os quais ele é confundido. Serão então apresentados alguns argumentos contra a regulação paternalista com especial enfoque nos problemas afetos ao próprio regulador e à atividade regulatória, que são oponíveis a ambas as formas de paternalismo regulatório. Como as medidas regulatórias paternalistas trabalhadas neste artigo são - como se acabou de dizer - apenas hipóteses teóricas para fins acadêmicos, não tendo sido (ao menos até o fim da conclusão deste trabalho) ainda cogitadas com seriedade pelas autoridades públicas, então os argumentos apresentados aqui também somente podem se limitar ao plano teórico. Ao fim, serão apresentadas breves conclusões.

\section{Razões paternalistas para regular}

Se o objeto deste artigo é uma forma de regulação paternalista, é preciso entender o que é regulação, o que é paternalismo, e como esses conceitos se relacionam. Em resumo, é preciso compreender como considerações de cunho paternalista podem ser consideradas razões para regular.

Inicialmente regulação foi entendida em um sentido mais estrito, como uma ação estatal necessária para correção de falhas de mercado e, deste modo, para a promoção de bem estar social em termos de eficiência alocativa de recursos (OGUS, 2004, p.29). Regulação era fundamentalmente vista como um conceito político-econômico e, como tal, poderia ser melhor entendida em referência aos diferentes sistemas de organização econômica e os mecanismos jurídicos que os mantém (PROSSER, 2010,p.2). O seu objetivo primordial era, portanto, de correção de falhas de mercado como monopólios naturais, externalidades, assimetrias informacionais, lucros inesperados, risco moral, bens públicos, sazonalidade, cream-skimming, poder desigual de barganha, entre outros (BALDWIN, CAVE, LODGE, 2012, p.15). Contudo, já há muito o conceito de regulação tem se expandido para incluir um número significativo de justificativas afetas a algum tipo de controle social, incorporando insights da sociologia e não só das ciências econômicas. Uma definição ampla bem difundida na literatura é a de Julia Black (2002, p.25), abarcando uma ampla gama de formas de 
tentativa de alteração do comportamento alheio a partir de standards, sem restringir um propósito ou mecanismo definido.

É este conceito expandido de regulação que será adotado para os propósitos deste artigo, o que a sua utilização em vez de uma categoria mais tradicional do Direito Administrativo, a do poder de polícia, pelo qual se manifestam limitações administrativas à liberdade e à propriedade (BANDEIRA DE MELLO, 2016, p.850). Entre nós o conceito de polícia administrativa está atrelado ao de "ciclo de polícia" compreendido pelas fases de ordem de polícia, consentimento de polícia, fiscalização de polícia e sanção de polícia (MOREIRA NETO, 2009, pp. 444ss). Tal ciclo corresponde em linhas gerais ao que se entende pela estratégia regulatória de comando e controle (BALDWIN, CAVE, LODGE, 2012, pp.106-111), o que potencialmente deixaria de fora da análise todo um rol de estratégias regulatórias potencialmente cogitáveis, como as de incentivos positivos e negativos, e de arquitetura de escolha (BALDWIN, CAVE, LODGE, 2012, p.105). Foi, portanto, para não vincular e potencialmente limitar a análise a uma forma apenas de medidas administrativas (mais ou menos) restritivas de liberdades que se optou por utilizar um conceito amplo de regulação, com sua miríada de estratégias regulatórias.

O paternalismo regulatório representa, em linhas gerais, a intervenção no comportamento de uma pessoa a fim de evitar que ela cause um prejuízo a si própria (VALDÉS, 1988, p.155). Para Victoria Camps (1988, p.185), é paternalista a ação de imiscuir-se na liberdade de outra pessoa com a intenção de defender seu bem. Gerald Dworkin (1972, p. 65), por sua vez, compreende paternalismo como a interferência coercitiva na liberdade de ação de uma pessoa justificada por razões que se referem exclusivamente ao bem estar, felicidade, necessidades, interesses ou valores da pessoa coagida. Joel Feinberg (1971, p. 105) afirma que “o princípio do paternalismo jurídico justifica a coerção estatal para proteger indivíduos de danos auto-inflingidos". Hart (1963, p. 31) trata o paternalismo como uma política de proteção das pessoas contra si mesmas.

Tais definições foram destacadas para que ficasse claro que é ponto fundamental do conceito de paternalismo ora adotado que a justificação da medida paternalista se refira exclusivamente a considerações a respeito do indivíduo cuja conduta se pretende tutelar. Assim, não estão abarcadas pelo conceito proposto normas que se justifiquem primariamente pela defesa de um interesse de terceiros ou da coletividade como um todo. Esse é o caso, por 
exemplo, das medidas restritivas de locomoção e aglomeração, típicas das estratégias de distanciamento e isolamento social, como fechamento de bares e restaurantes (ou permissão de que funcionem apenas com serviços de entrega), interdição de praias, parques e outros locais públicos. Medidas que têm como objetivo direto impedir a propagação do vírus em larga escala, relacionadas, portanto, à saúde pública.

De outra sorte, seria possível cogitar medidas paternalistas como eventuais normas que restringissem ou até mesmo proibissem a comercialização de determinado tipo de alimento ou bebida, por considerá-los prejudicial à saúde de seu consumidor. Por exemplo, caso a comercialização de bebidas alcóolicas fosse limitada a uma determinada quantidade de unidades por pessoa por vez nos estabelecimentos comerciais, ou se simplesmente houvesse um banimento da comercialização de tais bebidas. Aqui em tese o problema não é se as pessoas, de ressaca, irão procurar os estabelecimentos de saúde superlotando-os ainda mais, ou se o consumo prolongado de bebidas alcoólicas em quantidades relevantes pode levar a problemas hepáticos, por exemplo. O que primordialmente justificaria tais medidas seria, em tese, uma própria preocupação com o bem-estar das pessoas e suas famílias que permanecem em quarentena ou isolamento.

Argumentar que tais medidas, em tese preocupadas com a saúde individual, seriam na verdade justificadas por uma preocupação em reduzir a demanda pelos serviços de saúde e, assim, evitar uma maior saturação do sistema de saúde não invalida a análise empreendida neste artigo. Quando muito, se as questões de saúde individual podem sempre ser reduzidas a questões de saúde pública, significa apenas que os fundamentos paternalistas são apenas uma forma travestida de atingir objetivos coletivos; em outros termos, que os argumentos paternalistas não são em si suficientes para adoção das medidas, que não se fundamentariam sem uma razão coletivista que as desse suporte.

Também não faz parte do conceito aqui oferecido a questão, posta por Manuel Atienza (1988, p. 203), da não aceitação da norma ou conduta paternalista pelo indivíduo suposto beneficiário. Não importa se o indivíduo aceita ou não a norma, se ele concorda ou não que precisa ser regulado pelo Estado, basta que a norma ou conduta estatal restrinjam as possibilidades de ação do indivíduo tutelado. Por exemplo, a muito comum norma de trânsito que impõe o uso do cinto de segurança ou a que obriga os motociclistas a usarem capacete, por mais elogiáveis e por mais alto grau de aceitação social que possuam, são normas 
paternalistas pois limitam a possibilidade de escolha, a liberdade dos indivíduos. Igualmente não abrangidas no conceito ora proposto aquelas intervenções em pessoas consideradas incapazes pela lei ${ }^{5}$, ou o que Victoria Camps (1988, p. 196) chama de "paternalismo justo": coação e intervenção não devem ser confundidas com debilidade e incompetência, com incapacidade física ou psíquica. Por mais que o sentido comum ao termo pareça aplicável em tais casos, aqui não se fará referência a essas situações em que a lei geral e abstrata comanda um dever de proteção - da família e do Estado - a pessoas sobre as quais recai uma explícita presunção ${ }^{6}$ legal de que não possuem a capacidade cognitiva ou o amadurecimento necessário para praticar atos da vida civil ${ }^{7}$. Os conceitos e debates aqui levados a cabo, portanto, referem-se apenas a indivíduos dotados de plena capacidade segundo seu ordenamento jurídico. De qualquer modo, depreende-se que toda conceituação de paternalismo parte da consideração de que o "governo tem uma certa obrigação de proteger os indivíduos de sua própria confusão e irresponsabilidade" (BREYER 1998, p. 11), ou de que "a liberdade tem um custo, que é arcada pelos indivíduos que fazem escolhas ruins" (KAHNEMAN, 2012, p . $515)$.

Não é incomum também a percepção de que as pessoas frequentemente recorrem a forças externas, procurando auxílio para protegê-las de si mesmas, de seus próprios erros de julgamento. Há inclusive autores que tentam estabelecer quais os cenários de erros de julgamento legitimariam a intervenção paternalista e quais não justificariam. Hodson (1977, p. 62), por exemplo, identifica situações em que haveria um certo consenso quanto à possibilidade de intervenção paternalista: casos em que o agente está em ignorância (quanto ao dano), estresse emocional, compulsão e influência de substâncias, incapacidade mental, inconsciência, etc. O autor, entretanto, coloca a questão em termos diferentes dos postos aqui: ele menciona situações em que uma intervenção (pelo Estado ou por outro particular) seria

\footnotetext{
${ }^{5}$ Artigos $3^{\circ}$ a $5^{\circ}$ do Código Civil de 2002.

${ }^{6}$ Ao contrário da presunção implícita que há nas regras paternalistas, no sentido aqui adotado.

${ }^{7}$ A escolha pelo legislador de um critério objetivo temporal (a idade) é também bastante questionável, de modo que não faltam críticas quanto aos critérios em si estabelecidos. É tormentosa a questão da outorga de capacidade ao chamado "jovem adulto" para tomar decisões a respeito de assuntos vinculadas a sua autonomia existencial. (Cf. A discussão a respeito da possibilidade de objeção consciência para transfusão de sangue em jovens adultos testemunhas de Jeová: Fabio Carvalho Leite, "Liberdade de crença e a objeção à transfusão de sangue por motivos religiosos". In Revista do Ministério Público. Rio de Janeiro: MPRJ, n.41, jul/set 2011, p.74)
} 
moralmente justificável, permissível, não chegando a afirmar que ela seja obrigatória, como as chamadas bad samaritan laws ${ }^{8}$.

Por outro lado, é possível também cogitar de um conflito intertemporal entre as preferências dos indivíduos, que por isso racionalmente delegariam a sua liberdade de escolha a uma regra - o que justificaria, nesse caso, a intervenção regulatória (OGUS, 2004, p. 52). Por exemplo, indivíduos que são sujeitos a tentações, como álcool e drogas. Tais tentações podem conferir bastante prazer no curto prazo, mas que no longo prazo os agentes, racionais, sabem que serão fontes de arrependimento, quando o vício cobrar o seu preço com a deterioração em sua saúde ou outros custos, inclusive financeiros. A utilidade, em termos individuais, é maximizada se tais indivíduos consentirem antecipadamente na privação da exposição da fonte de tentação (LOOMES e SUGDEN, 1982, p. 205). Esse raciocínio tem sido estendido a áreas em que indivíduos notoriamente tomam escolhas consideradas irracionais. Argumenta-se que se eles tivessem sido capazes de perceber o que estava em jogo, eles teriam consentido à imposição da limitação de suas escolhas. O que esses argumentos parecem presumir é que há uma distinção entre os desejos e vontades reais (prazer de longo prazo como permanecer saudável) e os "aparentes" (como os prazeres imediatos) dos indivíduos, e que impor uma regulação paternalista seria meramente uma forma de garantir que os desejos e vontades reais prevaleçam (OGUS, 2004, p. 53).

Em verdade, com o avanço dos estudos sobre o processo de tomada de decisões e da chamada behavioral economics, refinou-se ainda mais o argumento fundado na falibilidade do raciocínio humano na tomada de decisões (JOLLS, SUNSTEIN e THALER, 1998, p. 1471). Esse aspecto tem muito a ver com outra razão reconhecida na literatura para regulação, a necessidade de correção de uma possível falha de mercado, ligada à racionalidade limitada (bounded rationality) dos agentes (BALDWIN, CAVE e LODGE, 2012, p. 74), considerando que não basta ser disponibilizada uma informação completa e correta por parte dos fornecedores de bens e serviços (ou seja, não basta que não haja problemas relativos à assimetria ou incompletude de informações), mas faz parte também das premissas para bom

\footnotetext{
${ }^{8}$ As bad samaritan laws são leis que obrigam indivíduos (muitas vezes sob pena de responderem a processo criminal) a prover auxílio a pessoas em grave perigo. No Brasil, há o emblemático exemplo do crime de omissão de socorro, previsto no artigo 135 do Código Penal (Art. 135 - Deixar de prestar assistência, quando possível fazê-lo sem risco pessoal, à criança abandonada ou extraviada, ou à pessoa inválida ou ferida, ao desamparo ou em grave e iminente perigo; ou não pedir, nesses casos, o socorro da autoridade pública: Pena - detenção, de um a seis meses, ou multa). Para uma análise de tais leis com enfoque no paternalismo jurídico, cf. MALM, 1995.
} 
funcionamento do mercado e sociedade que os agentes individuais sejam capazes de compreender e tomar decisões racionais com base em tais informações (OGUS, 2004, p.38).

Por ora, cabe avançar com uma simplificada definição, que resume o discutido até o momento. Considera-se, portanto, paternalista toda forma de regulação cuja justificativa leve em conta apenas considerações a respeito tão somente do próprio indivíduo e não de terceiros ou da coletividade. Apesar de muitas vezes as justificativas paternalistas não serem as únicas possíveis ou mesmo as invocadas expressamente nas discussões regulatórias, é possível assumir que o paternalismo permanece como uma motivação poderosa para a regulação mesmo quando outras justificações, como as externalidades, poderiam também ser aplicáveis (OGUS 2004, p. 52).

\section{Formas de regulação paternalista}

A regulação paternalista pode assumir duas formas, a depender do grau de interferência na conduta individual e da existência ou não de uma sanção pela não adesão, pelo indivíduo, à conduta esperada. Como visto, as formulações paternalistas tradicionalmente possuíam um forte elemento de intervenção e cominavam uma sanção para o seu descumprimento. É o chamado paternalismo coercitivo, forte, que lança mão primariamente de estratégias de comando e controle com sanções administrativas (como a perda de pontos na habilitação para dirigir pela não utilização de cinto de segurança) ou até a utilização do aparato criminal. Para Sarah Conly $(2013$, p.7), os dados empíricos que mostram as falhas na racionalidade humana são mais que suficientes para legitimar o uso da coerção, do poder punitivo estatal, inclusive penal. Nas suas palavras, o paternalismo é mais justificável que normalmente pensamos. Agora sabemos que somos incuravelmente irracionais, e isso não pode ser corrigido simplesmente com atenção.

Aplicando-se a teoria de Conly ao regulador paternalista hipotético nestes tempos de isolamento social, seria possível cogitar de medidas que procurem promover o bem estar de pessoas limitadas ao ambiente domiciliar. Por exemplo, a imposição de restrição de locomoção pode levar muitas pessoas a adotar uma conduta sedentária, assumindo como premissa que a esmagadora maioria das pessoas, em situações de normalidade, realiza suas atividades físicas fora de suas casas, seja em locais públicos como parques, praças, praias ou em academias. Medidas regulatórias de cunho paternalista desse tipo podem, por exemplo (i) limitar ou até mesmo restringir a aquisição de substâncias que possam causar algum mal à 
saúde, como alimentos de baixo teor nutritivo e alto teor calórico, bebidas alcóolicas ou cigarro; ou (ii) induzir ou incentivar a ingestão de alimentos saudáveis ${ }^{9}$ e a prática de atividades físicas mesmo em domicílio.

Práticas do tipo (i) utilizam estratégias de comando e controle, e são direcionadas tanto aos indivíduos em si que são objeto da proteção paternalista quanto aos fornecedores de bens e serviços que são objeto da restrição. Nessa versão mais coercitiva de regulação paternalista, a decisão regulatória é tomada mesmo onde fica evidente que os agentes regulados envolvidos não apoiariam as medidas regulatórias ainda que estejam em posse de todas as informações relevantes para o assunto (BALDWIN, CAVE e LODGE, 2012, p. 23). Ou seja, mesmo estando plenamente cientes do risco que há para a própria saúde, principalmente de problemas cardiovasculares na adoção de hábitos ruins de alimentação e de práticas sedentárias, ainda assim muitos indivíduos fariam uso de tais práticas, o que justificaria, para essa corrente paternalista mais radical, a intervenção regulatória.

Note-se que não se trata do mesmo que a regulação limitadora da quantidade passível de ser adquirida de equipamentos úteis à higienização. Cite-se, por exemplo, o Decreto 609, de 16 de março de 2020 do Estado do Pará, que em seu artigo $9^{\circ}$ dispõe que a comercialização do álcool em gel $70^{\circ}$ no Estado fica limitada a três unidades por consumidor. Esta norma não tem como preocupação a proteção em si dos indivíduos enquanto consumidores contra atitudes tomadas por ele mesmo; ela é destinada à proteção da saúde dos demais consumidores, considerando que o acúmulo de muitas unidades por poucos indivíduos (que estão muito possivelmente em isolamento domiciliar) pode levar ao esgotamento do estoque de tais produtos e a indisponibilidade para aqueles indivíduos que realmente necessitam (em especial aqueles que, pela natureza de sua atividade, não puderam aderir às práticas de isolamento). Em última instância, trata-se, na verdade, de medida protetiva da saúde pública, considerando que para evitar o contágio é importante que todos tenham acesso a produtos e práticas mínimas de higiene, e não que apenas um subconjunto possua muitos meios (ou muitas unidades do mesmo meio) de prevenção.

\footnotetext{
${ }^{9}$ Como a discussão sobre o conceito de regulação tida na Suprema Corte norte-americana no caso (Nat'l Fed'n of Indep. Bus. (NFIB) v. Sebelius, 132 S. Ct. 2566 (2012)) que declarou a constitucionalidade do Affordable Care Act, conhecido como "Obamacare": no caso, os Justices discutiram se a norma regulatória em questão, prevendo a obrigatoriedade de todos os americanos contratarem um seguro de saúde, seria equivalente a resolver o problema de dieta dos indivíduos obrigando todos a comprarem legumes e verduras.
} 
Deixando de lado as estratégias de comando e controle, há ainda as estratégias intermediárias, de indução de comportamentos, e o chamado paternalismo libertário, que procuram sempre que possível não obstruir o processo tomada de decisão individual (SUNSTEIN e THALER, 2003, p.177). Em relação às formas intermediárias e brandas de regulação paternalista, se percebermos regulação como um fenômeno social, será possível ver que muitos agentes, adotando diferentes instrumentos procuram atingir objetivos regulatórios em geral contraditórios ou conflituosos. Subsídios, taxas e cobranças vêm sendo utilizados ao mesmo tempo que padrões licenças e proibições. Seria, portanto, muito melhor falar de uma série de remédios regulatórios que podem ser adotados de forma flexível de acordo com os objetivos perseguidos (REICH, 2017, p.43). No caso em questão, seria possível cogitar de subsídios estatais a indivíduos que adotassem as práticas de exercícios desejada. Por exemplo, nos Estados Unidos da América, o Federal Bureau of Investigation (FBI) lançou, muito curiosamente, um aplicativo para telefonia móvel que instrui seus usuários a fazer exercícios físicos. ${ }^{10}$ Se a intenção do FBI é realmente prover uma melhor qualidade de vida à população americana ou, na realidade, apenas obter maiores informações sobre os usuários do aplicativo $^{11}$ já é questão que os crentes em uma regulação desinteressada e os adeptos da teoria da escolha pública irão divergir.

Já o paternalismo libertário, brando ou soft, lança mão amplamente de intervenções destinadas a induzir (nudge) comportamentos por meio da modelagem da "arquitetura de escolha" dos agentes cujo comportamento se pretende alterar (SUNSTEIN e THALER, 2008). A intenção é a de mostrar que melhor que obrigar o indivíduo a agir de determinada forma seria guia-lo para a escolha certa. Assim, essa corrente está mais preocupada em orquestrar o processo de tomada de decisão individual de modo que as pessoas possam fazer melhores escolhas. Por exemplo, colocando nas lanchonetes os produtos alimentícios mais saudáveis em altura acessível para as crianças e os produtos menos saudáveis mais embaixo ou no alto das prateleiras, de modo que seja mais provável que as crianças escolham os produtos saudáveis; ou fazendo que nas empresas a adesão a planos de previdência seja o padrão -, tendo que o empregado optar por sair ao invés de optar por entrar - conseguiu-se que mais

\footnotetext{
${ }^{10} \mathrm{https://www.fbi.gov/news/apps/fitnessapp.} \mathrm{Acesso} \mathrm{em} 9$ de maio de 2020.

${ }^{11}$ https://www.businessinsider.com/fbi-home-workout-fittest-app-tracks-location-data-privacy-2020-3.
} 
empregados poupassem melhor seu dinheiro do que no cenário anterior, em que eles tinham que ir atrás dos serviços de previdência.

Sunstein e Thaler usam com mais intensidade os estudos nas ciências comportamentais para desenvolver o que chamam de "arquitetura de escolhas" (SUNSTEIN e THALER, 2003, 2008). Os arquitetos deveriam, no processo de construção do cenário de escolhas, proceder a uma comparação utilizando uma análise de custo-benefício, privilegiando, assim, soluções de baixo custo para a liberdade individual, simplificando e melhorando a tomada de decisão, como por meio da exigência de informações obrigatórias. Vale notar que, para os autores, qualquer situação que possibilite a organização do contexto no qual pessoas fazem escolhas seria uma forma de paternalismo, quer por parte de agentes públicos ou privados (SUNSTEIN e THALER, 2008, p.30); seja o governo exigindo a destinação de parte dos salários para um fundo público de previdência, seja o dono da lanchonete que escolhe qual a ordem e localização dos produtos no balcão, algum tipo de paternalismo seria inevitável. Nesse sentido, de fato agentes privados são responsáveis por moldar o contexto em que se dão as escolhas de indivíduos - notadamente no âmbito da relação de consumo - mas o fazem levando em consideração seus próprios interesses (normalmente comerciais). Se tais interesses dependem indiretamente dos interesses de um determinado público alvo, isso não significa que houve uma substituição de interesses: se determinada lanchonete oferece apenas produtos saudáveis ou os expõe em destaque, ela o faz para conquistar um determinado público, esperando que tal estratégia lhe trará melhores resultados econômicos do que oferecendo produtos que não sejam saudáveis; ainda assim, o faz primariamente em seu interesse, não de seu consumidor.

O paternalismo brando (ou libertário) possui claras vantagens em relação ao seu coirmão coercitivo: em primeiro lugar, ele preserva a possibilidade de escolha do indivíduo, ainda que alterando o cenário em que essa escolha é feita; em segundo lugar, ele não prevê sanções aos indivíduos que "fazem a escolha errada", punindo apenas os "arquitetos" que não se conformam com o cenário que é entendido como o mais adequado. Tais diferenças são cruciais para as conclusões que serão ao final apresentadas.

\section{Os problemas da regulação paternalista}

Ocupar-se-á agora de considerações contra a regulação paternalista. O presente trabalho não irá focar tanto nos argumentos que se referem ao valor moral da autonomia do 
indivíduo, entendida como a capacidade de o sujeito determinar seu próprio comportamento, objeto da filosofia. O objetivo é demonstrar que a regulação de cunho paternalista traz consigo problemas intrínsecos de três ordens: alguns epistêmicos, outros institucionais e outros referentes ao próprio instrumental linguístico utilizado pelo direito. Razões essas que podem levar a falhas regulatórias, muitas vezes gerando resultados contrários ao propósito alegado das estratégias regulatórias (GRABOSKY, 1995, p.347). Afinal, como indicam Baldwin, Cave e Lodge (2012, p. 68), iniciativas regulatórias nascem em meio a esperança e otimismo, que eventualmente transformam-se em tristeza e decepção quanto a sua necessidade e efetividade.

\subsection{Críticas à capacidade do regulador}

O primeiro conjunto de argumentos diz respeito à capacidade dos próprios reguladores de chegar efetivamente às decisões que melhor atendam ao que se imagina serem os melhores interesses do regulado. O foco nesse estudo será em devolver aos reguladores o tipo de crítica à capacidade epistêmica feita aos agentes privados. ${ }^{12} \mathrm{Se}$ os estudos de psicologia social e economia comportamental identificam carências informacionais e cognitivas nos indivíduos que tomam decisões como algo intrínseco ao raciocínio humano, não seria o caso de investigar se tais carências afetam também agentes públicos enclausurados em seus escritórios? As falhas na cognição e tomada de decisão humana devem tornar o debate aberto também aos erros de agentes públicos, não só de agentes privados, argumentando que haveria boas razões para crer que a tomada de decisões na esfera pública é possivelmente mais falha que a na esfera privada (GLAESER, 2006).

Glaeser apresenta modelos econômicos em que demonstra sua hipótese, envolvendo os custos e incentivos em tomar decisões acertadas para tanto reguladores quanto para os indivíduos. Para ele, a falta de incentivos na atividade regulatória para tomar a melhor decisão para todo um conjunto de indivíduos, em comparação com os incentivos de cada indivíduo

\footnotetext{
12 Adicionalmente, apesar de não ser o foco deste estudo, destaca-se o conjunto de considerações de caráter institucional, críticas à capacidade institucional das entidades regulatórias. A chamada virada institucionalista no direito ganhou força após a publicação do artigo de Vermeule e Sunstein "Interpretation and Institutions" na Michigan Law Review (vol. 101, pp. 885-951, fev. 2003). Este conjunto de críticas institucionalistas pode ser entendida, em largos termos, pela proposição de que as estratégias interpretativas devam levar em consideração a capacidade da instituição responsável pela tomada de decisão. Nas hipóteses cogitadas neste artigo, por exemplo, seria o caso de questionar se entidades como a ANVISA, o Ministério da Saúde ou as secretarias estaduais e municipais de saúde seriam institucionalmente capazes de tomar essas decisões.
} 
para tomar as melhores decisões para si, bem como o número reduzido de tomadores de decisão públicos, sugerem que a decisão centralizada governamental é propensa a ser falha (2006, p.134). Essas falhas decorrem da aplicação ao próprio regulador - indivíduo ou colegiado, dos próprios questionamentos feitos pela economia comportamental em relação à tomada de ações individual.

É possível perceber, como mesmo Sunstein e Thaler reconhecem (2003, p.178), que muitas vezes o planejador centralizado não poderá fazer uma correta avaliação do que melhor promoverá o bem estar, especialmente por possuir pouca informação a respeito das preferências e consequências dos cenários regulatórios. Afinal, em última análise e levado ao extremo o argumento dos custos e assimetrias informacionais, é preciso reconhecer que é próprio indivíduo quem possui mais informações e a menores custos para a melhor tomada de decisão em cada caso, considerando que o regulador, por mais que munido de dados estatísticos, não possui os conhecimentos específicos que estão disponíveis somente aos indivíduos dispersos. ${ }^{13}$

Com isso não se pretende afirmar que os indivíduos sempre tomam decisões adequadamente informadas nem se quer negar toda a evidência apresentada pelas ciências comportamentais de que o pensamento humano pode muitas vezes cair em armadilhas e ser falho até mesmo quanto aos seus fins e valores mais importantes. O que se quer demonstrar aqui é que se verifica uma assimetria informacional gritante. Os agentes reguladores não possuem as informações no detalhe a respeito das preferências e interesses individuais (e obtê-las implicaria um custo incalculável) para uma adequada tomada de decisões. Os dados gerais obtidos e utilizados nas políticas paternalistas podem ser considerados condições necessárias porém não suficientes para decidir. Por outro lado, o mesmo pode ser dito do

\footnotetext{
13 "Só os indivíduos poderão conhecer plenamente as circunstâncias relativas a cada caso e a elas adaptar suas ações. Para que o indivíduo possa empregar com eficácia seus conhecimentos na elaboração de planos, deve estar em condições de prever as ações do estado que podem afetar esses planos. Mas, para que tais ações sejam previsíveis, devem ser determinadas por normas estabelecidas independentemente de circunstâncias concretas que não podem ser previstas nem levadas em conta de antemão - e os efeitos específicos dessas ações serão imprevisíveis. Por outro lado, se o estado dirigisse as ações individuais visando a atingir objetivos específicos, teria de agir com base em todas as circunstâncias do momento, e portanto suas ações seriam imprevisíveis. Daí o conhecido fato de que, quanto mais o estado "planeja", mais difícil se torna para o indivíduo traçar seus próprios planos." (HAYEK, F. A. O Caminho da Servidão. 6a edição. São Paulo: Instituto Ludwig von Mises, 2010, pp.91-92).
} 
indivíduo: as informações e preferências individuais são necessárias - mas muitas vezes não suficientes - para uma adequada tomada de decisões. ${ }^{14}$

De fato, muitas vezes o indivíduo mostra-se confuso e indeciso, podendo ser acrático, e isso pode até mesmo levar a sua infelicidade. O que se quer argumentar é que se muitas vezes o próprio indivíduo (que tem acesso a todas as informações de caráter subjetivo) não consegue definir o que é melhor para si, não será um burocrata encastelado em uma repartição pública - que apenas possui informações gerais, nunca específicas - que irá saber o que é melhor para todo e cada um dos administrados. Seria mais simples e viável pensar em meios de auxiliar os indivíduos informando-os - e são bem documentadas as estratégias regulatórias informacionais, de disclosure (BALDWIN, CAVE e LODGE, 2012, p.119) permitindo que façam decisões livres e fundamentadas, ainda que com o auxílio do Estado.

Um paternalista argumentaria, aqui, que as decisões governamentais são baseadas em inúmeros e extensos estudos que conseguiriam representar com satisfatória fidelidade o estado de determinada questão na sociedade, apresentada em seus estratos mais detalhados pelos critérios mais variados. Ainda que se conceda à regulação inquestionável qualidade em sua formulação, mesmo assim ela apenas poderá se referir a grupos (maiores ou menores, majoritários ou minoritários), mas nunca a indivíduos, quer por uma impossibilidade física de ter acesso a todas as preferências e necessidades dos indivíduos (até porque, como visto, muitas vezes nem os próprios sujeitos sabem ao certo o que querem), quer por uma impossibilidade lógica, ao perceber que qualquer pretensão de individualização esbarra no próprio caráter geral e abstrato da lei. Assim, a única saída para o paternalista é admitir que sempre haverá uma substituição aos valores do indivíduo - sejam eles valores compartilhados em um grupo minoritário, em toda sociedade ou simplesmente adotados e impostos pelo Estado.

\subsection{Incongruência de justificativas}

\footnotetext{
${ }^{14}$ Nesse ponto, não se perfilha do entendimento de Mill tal qual entendido (e criticado) por Valdés, de que o homem ou mulher mais comuns possuem meios de conhecimento que superam incomensuravelmente aqueles que podem possuir qualquer outro a respeito de seus interesses (VALDÉS, Ernesto Garzón. Op. cit. p.158). Concordar irrestritamente com Mill aqui significaria desconsiderar todas as descobertas das ciências comportamentais, o que não é o intuito do presente trabalho. Entretanto, uma leitura mais caridosa de Mill - de que as informações e preferências individuais são fatores indispensáveis em qualquer tomada de decisão - pode se aproximar do que é aqui defendido.
} 
Uma das dificuldades de se tratar do tema de falhas regulatórias diz respeito ao fato de que tais debates são normalmente baseados em diferentes concepções do que é "boa" regulação, para que, contrastada, se perceba onde houve alguma falha em atingir tal parâmetro (BALDWIN, CAVE e LODGE, p.69). Um dos elementos, contudo, em que se pode lastrear uma avaliação da regulação é a sua correspondência - ou congruência com as razões (de interesse público) que justificaram oficialmente a adoção da medida. Assim, o segundo conjunto diz respeito às justificativas reais da regulação. Em outros termos, trata-se de questionar se é realmente verificada a premissa (em tese) justificadora da ação paternalista de que a medida regulatória está sendo tomada nos interesses dos indivíduos (e não em outros interesses). Ora, se as chamadas teorias institucionais e da captura da regulação possuem fundamento, então a justificativa paternalista não tem força alguma, mas serve apenas como uma desculpa para o atendimento de interesses outros, dos próprios reguladores ou de terceiros (ORBACH, 2012, p.15).

Uma mera análise de incentivos pode demonstrar que, se o custo de persuadir um ou poucos burocratas detentores do poder regulatório é inferior que o custo de persuadir milhares de consumidores, chances são que os burocratas serão mais propensos a erros que os consumidores (GLAESER, 2006, p.134). Assim é que, apesar de reconhecer que há casos bem sucedidos de paternalismo, não se pode esquecer que, vez após vez, sob a carta branca das medidas paternalistas, reguladores têm abusado de sua posição decisora e atendido a interesses próprios ou de terceiros.

Tome-se como exemplo o caso dos cigarros eletrônicos: eles simulam o ato de fumar pela vaporização de substâncias flavorizantes, podendo possuir ou não nicotina. Por não possuírem as inúmeras substâncias maléficas à saúde humana que os cigarros tradicionais possuem, os cigarros eletrônicos vêm cada vez mais sendo utilizados como substitutos dos produtos tradicionais pelos dependentes químicos da nicotina, além de evitar que terceiros sejam prejudicados pela fumaça exalada, por eliminarem simplesmente vapor d'água. Assim, podem ser pensados tanto como produto derivado do tabaco ou como mecanismo de auxílio no combate à dependência de nicotina. Essa indefinição quanto a sua classificação é visível em diversos órgãos reguladores sanitários nacionais e internacionais. Se tidos como produtos fumígenos, concorrem com os produtos tradicionais da indústria tabagista; se tidos como uma 
modalidade de tratamento de reposição de nicotina, concorreriam em um mercado dominado por produtos das grandes indústrias farmacêuticas, como os adesivos e chicletes de nicotina ${ }^{15}$.

Considerando a justificativa (eminentemente paternalista) das normas que pretendem restringir a comercialização de tais produtos, é de se espantar que, como o Washington Examiner $^{16}$ indicou, sejam as grandes empresas da indústria farmacêutica - e não as grandes empresas de tabaco - os maiores lobistas pressionando governos (especialmente o governo federal norte-americano) em busca de mais intensa regulamentação. Não coincidentemente, foi nomeado para dirigir a área do $F D A^{17}$ relacionada a produtos de tabaco um dos mais respeitados lobistas da chamada Big Pharma, Mitch Zeller, que já foi consultor de empresas como a GlaxoSmithKline ${ }^{18}$. Em resumo: por trás de uma regulação com aparência paternalista, reside a proteção de interesses corporativos de um determinado setor da indústria, que busca dizimar a concorrência de produtos que rapidamente ganhavam mercado. Uma bela demonstração de captura do regulador por interesses do regulado (STIGLER, 1971).

$\mathrm{Na}$ verdade, esse tipo de postura cética em relação à regulação vai bastante em linha com a crítica contundente feita ao fenômeno regulatório a partir de uma perspectiva da teoria da escolha pública (public choice theory) que entende a atividade regulatória apenas como uma forma de proteção de interesses de determinados grupos (seja do mercado ou da sociedade civil). Trata-se da hipótese (ou percepção) de que a regulação é, nas palavras de Stewart (1983, p.1543), uma self-serving tool, manipulada seja por grupos econômicos bem organizados para aumentar sua renda ou por facções ideológicas desejosas de impor seus valores na sociedade.

Nesse sentido, mesmo que autores como Sarah Conly se recusem a admiti-lo, a defesa de qualquer forma de paternalismo regulatório implica algum tipo de imposição de

\footnotetext{
15،“(A terapia de substituição nicotina) é considerada um método seguro no tratamento da dependência de nicotina, o mais popular e o menos dispendioso. Quando comparada com placebo, é mais efetiva, influenciando também a frequiência das recaídas. Esse tratamento pode ser aplicado por quatro formas de apresentação do produto com nicotina: a goma de mascar, o sistema transdérmico, o spray nasal e o vaporizador oral." MARQUES, A.C.P.R. et al. "Dependência de nicotina" in Revista Brasileira de Psiquiatria Vol. 23, n.4, 2001, p.207.

${ }^{16} \mathrm{http} / / /$ washingtonexaminer.com/big-pharma-not-tobacco-companies-wages-war-on-electroniccigarettes/article/2539441. Acesso em 09 de maio de 2020.

${ }^{17}$ U S Food and Drug Administration, agência reguladora sanitária federal norte-americana e um dos mais importantes órgãos do setor no mundo.

${ }^{18}$ Informação contida na matéria do Washinton examiner indicada supra.
} 
valores, com a substituição dos valores dos indivíduos pelos valores do regulador. Tal fato fica mais evidente quando se percebe - como já exposto - que a maioria das regulações paternalistas não pretende resguardar ou ampliar a liberdade do indivíduo, mas tutelar algum bem, interesse ou valor que é considerado relevante. Ao contrário, a função da regulação deveria ser a de uma mediação ativa dos diversos interesses contrapostos (MARQUES NETO, 2002, p. 177), mantendo a neutralidade quanto aos fins, limitando-se oferecer os meios que permitam que os indivíduos busquem por si os seus objetivos (HAYEK, 1985, p.3). Na esteira da lição de Feinberg (1986, p.12), a lei não deve se preocupar com a sabedoria ou a prudência de uma escolha individual, mas se a escolha é verdadeiramente do indivíduo.

\subsection{Problemas inerentes ao Direito}

O terceiro tipo de problemas que poderiam afetar as medidas regulatórias hipotéticas cogitadas para a presente análise diz respeito à estrutura operativa das normas regulatórias aplicadas, em especial à indeterminação e à inclusividade de tais normas (BALDWIN, CAVE e LODGE, p.69). As questões analisadas nessa seção dizem respeito, na verdade, a problemas da linguagem ordinária e da utilização de generalizações na formulação de normas (SCHAUER, 1991, p.15).

Normas jurídicas do tipo regras estão baseadas em generalizações para a formação de seus predicados fáticos, estes a hipótese de aplicação da norma (CHRISMANN, 2016a, p.8). Tais generalizações são apenas assunções probabilísticas de uma relação entre os propósitos que se pretendem alcançar com a regra e as medidas necessárias para fazê-lo. É a generalidade que é responsável pelo fenômeno da subinclusão ou sobreinclusão das regras ou pela sua potencial sobreinclusão ou subinclusão. (STRUCHINER, 2005, p. 147). Isso porque as normas, em particular as regras, incorporam mais casos do que deveriam, ou deixam de incorporar casos que deveriam incorporar para concretizar as suas justificações subjacentes, gerando, assim, resultados subótimos em certas ocasiões (CHRISMANN, 2016b p.40).

Ilustrativamente: uma medida que proíbe ou limita a aquisição de certos tipos de alimentos de baixo teor nutritivo sob a justificativa de proteção da saúde dos indivíduos sedentérios em regime de isolamento domiciliar é ao mesmo tempo sub e sobreinclusiva. Subinclusiva pois, por mais exaustiva que possa ser a lista, ela certamente deixará de fora alguns alimentos que, ainda que não sejam prejudiciais em si, podem vir a ser prejudiciais à saúde em certas doses (por exemplo, o sal). Por outro lado, é também sobreinclusiva, pois 
afeta situações que não caem no escopo de sua justificativa, como os atletas ou pessoas que já praticam exercícios em casa e que não sofreriam tanto os efeitos de uma alimentação eventualmente inadequada.

Nesses casos, a aplicação da regra produz uma situação indesejada, já que as suas justificativas apontam para resultados diferentes dos apontados pelos predicados fáticos ou pelas generalizações, de modo que o caráter subótimo de tais normas representa mais um argumento contrário à sua adoção. A contribuição original deste trabalho decorre justamente do reconhecimento que medidas paternalistas são um bom exemplo de norma que demanda uma particular preocupação com sua congruência (DIVER, 1983, p.66), e que esta é desatendida em decorrência dos problemas apontados.

Assim, mesmo as versões mais brandas de paternalismo regulatório estão sujeitas a tais problemas, visto que não identificam exatamente quando seria apropriada uma intervenção regulatória. Nas palavras de Ogus (2004, p.53):

\section{Although in theory interventionist measures can be formulated so that choices are imposed only where it is demonstrated in the particular circumstances that an individual's decision-making abilities are inadequate, such a case-by-case approach would be impracticable because of the high transaction costs involved. Paternalist regulation, therefore, has to proceed by applying uniform controls on certain activities where it is assumed that many individuals make unwise decisions. The imprecision of targeting means that some individuals who are well equipped in the relevant areas to make decisions in their own best interests are deprived of choice}

Note-se que esses problemas de sub e sobreinclusão são oriundos da determinação de normas. Outro problema pode ainda acometer as hipotéticas medidas regulatórias é o da indeterminação, o que acontece, principalmente, quando se faz uso de conceitos vagos (CHRISMANN, 2016, p.9). Conceitos ou predicados vagos são aqueles que possuem como marca registrada a característica de apresentarem casos fronteiriços ou nebulosos de aplicação. A vagueza pode ser urna vagueza de grau ou combinatória, quando o conceito é multidimensional; ou seja, seu significado depende de uma série de propriedades constitutivas. (STRUCHINER, 2011, p.137). É possível cogitar, no caso, de problemas de 
vagueza de grau que acometeriam medidas regulatórias paternalistas que modelassem o cenário de escolha de consumidores de forma a promover a aquisição de "alimentos nutritivos", ou que limitassem a possibilidade de aquisição por um consumidor de alimentos "não saudáveis"; ou que oferecessem incentivos a pessoas "obesas" que praticassem exercícios físicos. Em todos esses casos, por causa da indeterminação prevalente, haveria dúvidas relevantes a respeito dos casos em que as normas seriam aplicáveis: quão nutritivo ou saudável um alimento precisaria ser e quão acima do peso uma pessoa precisaria estar para serem aplicáveis as normas é questão tormentosa decorrente da vagueza de grau dos citados termos.

\section{Conclusões}

A proposta do presente estudo foi a de apresentar três tipos de objeções a medidas regulatórias paternalistas que hipoteticamente podem ser cogitadas em tempos de pandemia. Procurou-se conceituar regulação (justificando a escolha de tal conceito e não de poder de polícia) e paternalismo, demonstrando que não há apenas uma forma coercitiva (que se utiliza de estratégias regulatórias de comando e controle) de paternalismo, mas também uma forma branda ou libertária.

Ao longo do estudo, foram desenvolvidos argumentos que demonstram que a regulação paternalista em geral não oferece respostas convincentes aos problemas que ele se propõe a resolver. $\mathrm{O}$ primeiro diz respeito à capacidade dos próprios reguladores de chegar efetivamente às decisões que melhor atendam ao que se imagina serem os melhores interesses do regulado, com foco nas críticas à capacidade epistêmica dos agentes reguladores - não só as mesmas críticas que a economia comportamental levanta contra a capacidade dos agentes no mercado, e que podem ser usadas de justificativa para a regulação, mas também considerando a inafastável assimetria informacional entre reguladores e regulados, bem como os custos incalculáveis que os reguladores teriam de obter as informações necessárias. Além disso, foram notadas as críticas às capacidades institucionais dos reguladores.

Já o segundo conjunto diz respeito às justificativas reais da regulação. Em outros termos, trata-se de questionar se é realmente verificada a premissa (em tese) justificadora da ação paternalista de que a medida regulatória está sendo tomada primordialmente nos interesses dos indivíduos regulados, e não em outros interesses - seja o de grupos de 
interesse, como indica a teoria da captura da regulação, ou dos próprios reguladores, considerados institucionalmente ou individualmente nas suas respectivas instituições.

Por fim, foram destacados problemas inerentes ao uso do direito, como os de sub e sobreinclusão, em que as regras que veiculariam as medidas regulatórias paternalistas hipotéticas potencialmente incorporariam mais casos do que deveriam, ou deixariam de incorporar casos que deveriam incorporar para concretizar as suas justificações subjacentes. Além das questões relativas à inclusividade, foram avaliados problemas de indeterminação, decorrentes da vagueza de termos potencialmente empregados nas medidas que se poderia cogitar.

Com a presente análise, procurou-se demonstrar que há objeções que transpassam todas as formas de regulação paternalista. Apesar de ser louvável a preocupação do paternalismo libertário em colocar o indivíduo na melhor posição possível para a tomada de decisão, ainda assim, para além das críticas tradicionais feitas às formas de paternalismo coercitivo que o próprio paternalismo libertário incorpora, ele mesmo sofre com problemas intransponíveis. Conclui-se, portanto, que são desaconselhadas quaisquer medidas regulatórias de caráter paternalista, independentemente da estratégia adotada.

\section{Referências}

ATIENZA, Manuel. "Discutamos sobre Paternalismo". In Doxa: Cuadernos de Filosofía del Derecho, n 5, 1988. Disponível em < http://bib.cervantesvirtual.com/FichaObra.html?Ref=15294 >. Acesso em 09/04/2020.

BALDWIN, Robert; CAVE, Martin; LODGE, Martin. Understanding Regulation. Theory, Strategy, and Practice. 2a ed. Oxford: Oxford University Press, 2012

BLACK, Julia. “Critical Reflections on Regulation', Australian Journal of Legal Philosophy 27 (2002)

BOGOSSIAN, Andre; DE LUCA, Alexandre. "Proibindo o proibido: problemas do paternalismo regulatório e a RDC $\mathrm{n}^{\circ}$ 14/2012 ANVISA". BDA - Boletim de Direito Administrativo, São Paulo, NDJ, ano 31, n. 2, fev. 2015

BREYER, Stephen (et al.) Administrative Law and regulatory policy: problems, text and cases. $4^{\text {th }}$ ed. New York: Aspen Publishers, 1998

CAMPS, Victória. "Paternalismo y bien común" in Doxa: Cuadernos de Filosofía del Derecho, $\mathrm{n} \quad 5, \quad 1988, \quad$ p. $195 . \quad$ Disponível em <http://rua.ua.es/dspace/bitstream/10045/10874/1/Doxa5_10.pdf>. Acesso em 9/04/2020

CHIRSMANN, P.H.V. "Julieta não está pronta para ser Montecchio - a união das famílias jurídicas e a necessidade de uma nova metodologia do direito preocupada com precedentes". Revista de Direito Brasileira. v. 14, n. 6, maio/ago. 2016, pp.3-17 
fenômeno punitivo. Saarbrücken: Novas Edições Acadêmicas, 2016

CONLY, Sarah. Against Autonomy: Justifying Coercive Paternalism. Camridge: Cambridge University Press, 2013

DIVER, Colin. "The Optimal Precision of Administrative Rules". Yale Law Journal, Vol. 93, No. 1, nov 1983.

DWORKIN, Gerald. "Paternalism”. In The Monist, v.56, n.1, Janeiro 1972,

FEINBERG, Joel. "Legal Paternalism" in Canadian Journal of Philosophy v.1, n. 1, Setembro 1971

Harm to Self. New York: Oxford University Press, 1986

GLAESER, Edward. "Paternalism and Psychology". In The University of Chicago Law Review 73, 1, 2006: 133-156

GRABOSKY, P.N, 'Counterproductive Regulation' in International Journal of the Sociology of Law, 23, 1995, 347-69;

HART, H.L.A. Law, Liberty and Morality. Stanford: Stanford University Press, 1963.

HAYEK, F.A. Direito, Legislação e Liberdade, Volume 2, São Paulo: Visão, 1985.

HODSON, John. "Principles of Paternalism". In American Philosophical Quarterly, Vol. 14, No. 1. Janeiro 1977,

JOLLS, Christine; SUNSTEIN, Cass; THALER, Richard. "A Behavioural Approach to Law and Economics", 1998, 50 Stanford Law Review 1471

KAHNEMAN, Daniel. Rápido e Devagar: duas formas de pensar. Rio de Janeiro: Objetiva, 2012

LOOMES, Graham e SUGDEN, Robert, "Regret Theory: An Alternative Theory of Rational Choice Under Uncertainty”, Economic Journal n. 92, 1982

MALM, H. M. "Liberalism, bad samaritan law and paternalism". In Ethics, V. 106, n. 1, outubro 1995, pp. 4-31

MARQUES NETO, Floriano de Azevedo. Regulação Estatal e Interesses Públicos, São Paulo, Malheiros Editores, 2002, p.177.

OGUS, Anthony. Regulation: legal form and economic theory. Oregon: Hart Publishing. 2004

PROSSER, Tony "Two visions of regulation", paper for "Regulation in the Age of Crisis, University College Dublin, June 2010

REICH, Norbert. "A crise regulatória - ela existe e pode ser resolvida?" in Regulação Econômica e Democracia: O Debate Europeu. Paulo Todescan Lessa Mattos (coordenação), 2a edição revista, São Paulo, Editora Revista dos Tribunais, 2017

STEWART, Richard, "Regulation in a Liberal State: the role of non-commodity values", Yale Law Journal, Vol. 92, No. 8, Jul., 1983, 
STIGLER, George J. "The Theory of Economic Regulation". The Bell Journal of Economics and Management Science. Vol. 2, No. 1 (Spring, 1971), pp. 3-21

STRUCHINER, Noel; CHRISMANN, Pedro H. V.. Aspectos filosóficos e psicológicos das punições: reunindo algumas peças do quebra-cabeça. Cad. CRH, Salvador, v.25, n.spe 2, p.133-150, 2012. Acesso em 09/04/2020. https://doi.org/10.1590/S0103$\underline{49792012000500010}$

STRUCHINER, Noel. Para falar de regras - O positivismo conceitual como cenário para uma investigação filosófica acerca dos casos difíceis do Direito. 2005. Tese de Doutorado disponível em: http://ged1.capes.gov.br/CapesProcessos/919300-ARQ/919300 5.PDF. Acesso em 09/04/2020.

Indeterminação e Objetividade: Quando o Direito diz o que Não Queremos Ouvir. In MACEDO Jr. Ronaldo Porto e BARBIERI, Catarina Direito e Interpretação: racionalidades de instituições. São Paulo: Saraiva, 2011, pp.119-152

VALDÉS, Ernesto Garzón. “¿Es éticamente justificable el paternalismo jurídico?” in Doxa: Cuadernos de Filosofía del Derecho, n 5, 1988. Disponível em http://bib.cervantesvirtual.com/FichaObra.html?Ref=15291. Acesso em 09/04/2020. 